\title{
Comparação da classificação de ocupação do solo do município de Frederico Westphalen-RS, utilizando os métodos Isodata e Distância mínima
}

\author{
Ana Claudia Guedes SILVA ${ }^{1}$, Gabriel de Menezes TREVISAN²
}

\author{
${ }^{1}$ Programa de Pós-Graduação em Engenharia Agrícola, Universidade Estadual do Oeste do Paraná, Cascavel, PR, Brasil. \\ ${ }^{2}$ Mestre em Engenharia Ambiental, Universidade Federal de Santa Maria, Santa Maria, RS, Brasil. \\ *e-mail: anaa_guedess@hotmail.com
}

Recebido em fevereiro/2019; Aceito em junho/2019.

\begin{abstract}
RESUMO: O uso dos Sistemas de Informações Geográficas (SIG), em produtos de sensoriamento remoto, tem sido cada vez mais utilizadas no mapeamento terrestre, facilitando na obtenção de informações espaciais. $\mathrm{O}$ objetivo deste trabalho foram avaliar duas diferentes técnicas de classificação digital, para o mapeamento de uso do solo do município de Frederico Westphalen - RS. Para este fim, utilizou-se o software Quantum Gis 2.18.13 (QGis) para primeiramente realizar a composição de bandas, realce de contraste e recorte da imagem de satélite Sentinel-2A (10m de resolução espacial) aos limites do município em estudo. Aplicaram-se diferentes técnicas de classificação digital: 1) Mínima Distância (supervisionada) e 2) ISODATA (não supervisionada); sendo o 1 realizado no QGis e o 2 no software ArcGIS 10.5. Foram obtidos mapas com diferentes informações, dos quais a acurácia foi avaliada pelos Índice Kappa, Exatidão Global, Erros de Omissão e Comissão. Constatou-se, pela análise dos valores das classes temáticas, $\mathrm{em} \mathrm{km}^{2}$, que os melhores resultados foram obtidos para a classificação supervisionada, a qual apresentou mais concordância com o mapa visual considerado a verdade de campo. Já para a validação a mesma classificação se destacou com maiores valores de Exatidão Global e Índice Kappa, $(63,41 \%$ e $45 \%)$ diferente do encontrado para a classificação ISODATA (48,17\% e 31\%).
\end{abstract}

Palavras-chave: geoprocessamento; sensoriamento remoto; classificação digital; mapeamento.

\section{Comparison of the classification of land use of the municipality of Frederico Westphalen - $\mathrm{RS}$, using the Isodata and Minimum distance}

\begin{abstract}
The use of Geographic Information Systems (GIS) in remote sensing products has been increasingly used in terrestrial mapping, making it easier to obtain spatial information. The objective of this work was to evaluate different digital classification techniques for the land use mapping of the municipality of Frederico Westphalen - RS. For this purpose, the software Quantum Gis 2.18.13 (QGis) was used to first perform band composition, contrast enhancement and cut-off of the Sentinel-2A satellite image (10m spatial resolution) at the boundaries of the studied municipality. Different digital classification techniques were applied: 1) Minimum Distance (supervised) and 2) ISODATA (unsupervised); 1 being done in QGis and 2 in ArcGIS 10.5 software. We obtained maps with different information, of which the accuracy was evaluated by the Kappa Index, Global Accuracy, Errors of Omission and Commission. The best results were obtained for the supervised classification, which presented more agreement with the visual map considered the truth of the field, by analyzing the values of the thematic classes in $\mathrm{km}^{2}$. For the validation, the same classification stood out with higher values of Global Accuracy and Kappa Index, $(63.41 \%$ and $45 \%)$ than that found for the ISODATA classification (48.17\% and $31 \%)$. However, the thematic classification should be adjusted as well as changing the RGB band composition to improve the statistical parameters.
\end{abstract}

Keywords: geoprocessing; remote sensing; digital classification; mapping.

\section{INTRODUÇ̃̃O}

As ações antrópicas possuem grande potencial de alteração do ambiente terrestre, como a exploração de recursos e a ocupação do espaço geográfico (GLATZLE, 2014). Assim, a necessidade de identificar o uso e ocupação de áreas vem crescendo ao longo dos anos, bem como métodos para melhor identificá-las de forma rápida e precisa.

Entre as diversas ferramentas existentes no geoprocessamento, a classificação digital de imagens de satélite torna-se uma ótima opção, já que seu processo se baseia na distinção e identificação de diferentes classes que possuem comportamentos espectrais diferenciados entre si, os quais permitem a sua classificação automatizada, em tempo hábil (JENSEN, 2009).

Para que isso ocorra, algoritmos de classificação ou classificadores são utilizados para extrair as áreas de interesse a partir de um espaço, geralmente representado por bandas da imagem, transformando em um nível de informação temática de classes de ocupação e uso de solo (ANDRADE et al., 2014).

Para classificar imagens, existem basicamente dois métodos: a classificação supervisionada, onde o usuário identifica alguns pixels pertencentes a determinadas classes desejadas para o estudo (amostragem) e o computador localiza todos os demais pixels semelhantes, tendo como base um 
algoritmo preestabelecido; e a classificação não supervisionada, onde a decisão é realizada pelo próprio computador, baseada também em algoritmos, em quais classes serão divididos os pixels (SOARES et al., 2016).

Segundo Bernardi et al (2007), os algoritmos mais corriqueiramente utilizados na classificação de imagens para uso e ocupação do solo são os não supervisionados Kmédias e ISODATA, e os supervisionados Máxima Verossimilhança (MAXVER), Distância Mínima, Paralelepípedo e Distância Mahalanobis.

Desta maneira, este trabalho tem como objetivo comparar a classificação de ocupação do solo do município de Frederico Westphalen - RS, através do mapa visual, obtido por interpretação da imagem de satélite Sentinel-2A, com os métodos não supervisionado ISODATA e supervisionado Distância Mínima, tendo como base classes temáticas ordinárias e suas áreas obtidas em cada categoria, analisando os parâmetros estatísticos índice Kappa, Exatidão Global (EG) e avaliação da acurácia por meio dos erros de omissão e comissão, encontrados a partir do cruzamento dos mapas visual e classificação.

\section{MATERIAL E MÉTODOS}

A elaboração deste estudo seguiu as seguintes etapas principais: 1) revisão bibliográfica e cartográfica sobre metodologias de uso e ocupação do solo e informações físiconaturais sobre a área de estudo; 2) aquisição dos produtos de sensoriamento remoto; 3) escolha e realização dos classificadores supervisionado e não-supervisionado; 4) criação e análise dos mapas de classes de uso e ocupação do solo e avaliação dos parâmetros estatísticos dos shapes.

A área estudada, Frederico Westphalen, é um município brasileiro localizado no estado do Rio Grande do Sul, na latitude $27^{\circ} 21^{\prime} 33^{\prime \prime}$ Sul e longitude 53 $23^{\prime} 40^{\prime \prime}$ Oeste, estando a uma altitude média de 566 metros do nível do mar e área de $265,21 \mathrm{~km}^{2}$ (IBGE, 2010).

O munícipio, é o maior da microrregião do Médio Alto Uruguai e também o $6^{\circ}$ maior produtor de soja do estado (EMATER/RS, 2018). É delimitado ao norte pelo Rio da Várzea - divisa com Iraí, no Norte do Estado. (Figura 1).

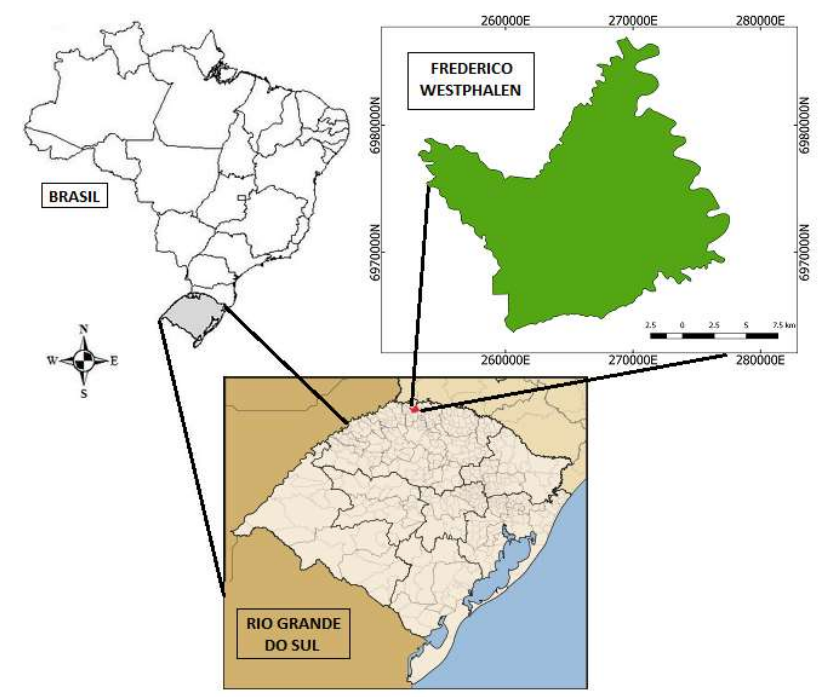

Figura 1. Localização do município de Frederico Westphalen - RS - Brasil.

Figure 1. Location of the municipality of Frederico Westphalen - RS - Brazil.
As imagens de satélite foram adquiridas gratuitamente no site de distribuição de produtos de sensoriamento EarthExplorer da National Aeronautics and Space Administration (NASA). Essa missão tem por objetivo produzir imagens de média resolução para fins de planejamento, possuindo bandas espectrais de 10, 20 e $60 \mathrm{~m}$ de resolução espacial que cobrem um campo de visão de 290 $\mathrm{km}$, sendo sua resolução temporal de 5 dias (contando para isso com dois satélites) (MEER et al., 2014).

Foram utilizadas imagens da missão Sentinel-2A da ESA (European Space Agency) do sensor MSI (multi-spectral instrument) de resolução espacial de $10 \mathrm{~m}$ (órbita 52), em que as bandas 3, 2 e 1 são do espectro visível e correspondem às cores vermelho, verde e azul, respectivamente (OLIVEIRA et al., 2017).

Os procedimentos de filtro, processamento de imagem supervisionada e edição final dos mapas e verificação da qualidade das classificações foi realizada no software Quantum Gis 2.18.13 (QGis). Já para a classificação não supervisionada usou-se o software ArcGIS 10.5.

Segundo Silva; Liporace (2016) a presença de nuvens e sombras na imagem ocasiona problema de oclusão de feições, reduzindo a área útil da imagem, bem como na análise quantitativa, pois, os pixeis interferidos por nuvem e sombra são tratados como válidos, que por sua vez, contaminam os valores calculados e aumentam o erro de classificação. Assim, escolheu-se trabalhar com imagens sem nuvens e sombras; e de fácil distinção entre regiões de mata e agricultura, bem como, recentes, selecionando as imagens obtidas no dia $12 / 12 / 2017$, período de ocorrência do cultivo da cultura da soja, importando-as para o software QGis e aplicando uma composição colorida multibanda RGB composta pela combinação das bandas R3G2B1, gerando assim uma imagem cor verdadeira com três bandas multiespectrais.

Contudo, aplicou-se o filtro realce de contraste linear de $2 \%$ na imagem para destacar as características da vegetação, principalmente o seu grau de densidade, onde os níveis de cinza foram distribuídos uniformemente pelo histograma, colaborando com melhor qualidade visual, e facilitando na interpretação visual e digital das informações representadas na imagem.

Após a composição e o realce, efetuou-se o recorte da imagem utilizando-se um arquivo shapefile do tipo polígono que caracteriza os limites do município de estudo, estando disponível na base de dados do IBGE, e, por conseguinte, o recorte no limite do município.

Baseou-se para a criação dos mapas de uso e ocupação do solo, na classificação temática de Ferreira et al. (2017), que apresenta as seguintes características:

i. Vegetação arbórea: Caracterizada pela presença de árvores de altura e densidade considerável, onde a água é previamente interceptada pelo corpo das mesmas;

ii. Vegetação rasteira: Consiste em um conjunto de gramíneas e/ou plantas de pequeno porte, incluindo áreas agrícolas e vegetação de pequeno porte;

iii. Área urbanizada: Em sua maioria, constituída pela área urbanizada da cidade, conforme definido pelo IBGE (2015);

iv. Solo exposto: Área composta somente por solo totalmente "nu", desprovido de qualquer tipo de recobrimento vegetal ou construção, e;

v. Corpos hídricos: Pode ser tanto uma lagoa (açude) ou um córrego fluvial. 
Em seguida, sucedeu-se a vetorização das feições, criando assim o mapa visual em shapefile, considerado posteriormente como o mapa base, que conteve as cinco classificações descritas anteriormente e após, realizou-se a classificação supervisionada e não supervisionada através das técnicas Mínima Distância e ISODATA.

Para a classificação supervisionada utilizou-se o complemento Semi-Automatic Classification Plugin (SCP) constante no repositório QuantumGis, escolhendo-se o método Mínima Distância, que exige a coleta de amostras para treinamento (BRASILIERO et al., 2016). Segundo o Instituto Nacional de Pesquisas Espaciais - INPE (2018) é necessário um número razoavelmente elevado de pixels, para cada conjunto de treinamento, esse número permite uma base segura para tratamento estatístico. Desta forma, foram feitas 176 amostragens poligonal para a realização do mesmo.

Já para a classificação não supervisionada utilizou-se a ferramenta ISODATA no ArcGIS, onde para a realização da classificação, selecionou-se a opção de cinco classes temáticas.

Para avaliar o desempenho dos classificadores, adotou-se a metodologia citada por Vale et al. (2018) chamada de painel amostral que se caracteriza pela distribuição aleatória de pontos amostrais dentro do limite do município, com o objetivo de se realizar um levantamento da classe de cada ponto.

Assim, no software QuantumGis foram gerados 164 pontos amostrais, servindo esses de referência terrestre. A avaliação dos pontos para se determinar a qual classe eles eram pertencentes, foi realizada por inspeção visual através da verdade de campo.

A verificação de acurácia foi realizada a partir do cálculo da matriz de confusão para a obtenção do Índice Kappa, Exatidão Global (EG), acurácias do produtor e do usuário. Neste processo, foi realizado a comparação entre a verdade terrestre e os dados resultantes da classificação digital, e com isso, pôde-se observar se os pixels foram corretamente classificados, bem como os erros de comissão e de omissão (MATSUKUMA, 2002).

É satisfatório a utilização do Índice Kappa na avaliação da precisão de uma classificação temática, pelo fato de levar em consideração toda a matriz de confusão no seu cálculo, inclusive os elementos de fora da diagonal principal, os quais representam as discordâncias na classificação, sendo calculado conforme a Equação 1. Após a obtenção dos índices, os valores foram associados a qualidade da classificação de Landis e Koch (1977).

$$
K=\frac{\left[n * \sum_{i=1}^{r} x i j-\sum_{i=1}^{r}(x i * x j)\right]}{\left[n^{2}-\sum_{i=1}^{r}(x i * x j)\right]}
$$

em que: $K=$ Índice de exatidão Kappa; $r=$ número de linhas na matriz, é o número de observações na linha $(i)$ e coluna (j); $n=$ número total de observações.

Já a Exatidão Global (EG) é a medida mais simples de verificação da proximidade de uma determinada medida ao seu valor real, em que relaciona os elementos da diagonal principal (concordância real) com o total de pontos amostrados da imagem classificada, sendo dada pela Equação 2.

$$
E G=\frac{A}{n} * 100
$$

em que: $E G=$ Exatidão Global; $A=$ número de pontos amostrais com acerto; $n=$ número de pontos amostrais.

Outro meio de obter a acurácia é através dos coeficientes de concordância para classes individuais, sendo eles: acurácia do produtor e do usuário, que se referem aos erros de omissão e comissão (ANDRADE et al., 2014).

Os erros de omissão são considerados como uma análise mais rigorosa pois levam em consideração os valores nas células marginais da matriz. No caso das linhas, os valores indicam o número de amostras que, pertencendo a uma determinada categoria, não foram incluídos (Equação 3).

$$
E o=\frac{+\mathrm{Xi}-\mathrm{Xii}}{+\mathrm{Xi}}
$$

em que: $E o=$ erro de omissão; $+X i=$ valor na marginal da linha; $X i i$ $=$ número na diagonal daquela linha.

Já o Erro de Comissão são os valores das células nas diagonais das colunas, isto é, pixels que não se incluem em uma determinada categoria, pertencente realmente a outra, sendo calculados conforme a Equação 4.

$$
c=\frac{+\mathrm{Xk}-\mathrm{Xii}}{+\mathrm{Xk}}
$$

em que: $E c=$ erro de comissão; $+X k=$ valor na marginal da coluna; $X i i=$ número na diagonal daquela coluna.

\section{RESULTADOS}

Os resultados foram obtidos e analisados em três etapas distintas. Assim, foi possível melhorar a visualização e qualidade dos objetos da imagem, destacando principalmente a vegetação, e com isso, facilitou a interpertração da imagem sob os critérios subjetivos do olho humano (Figura 2).

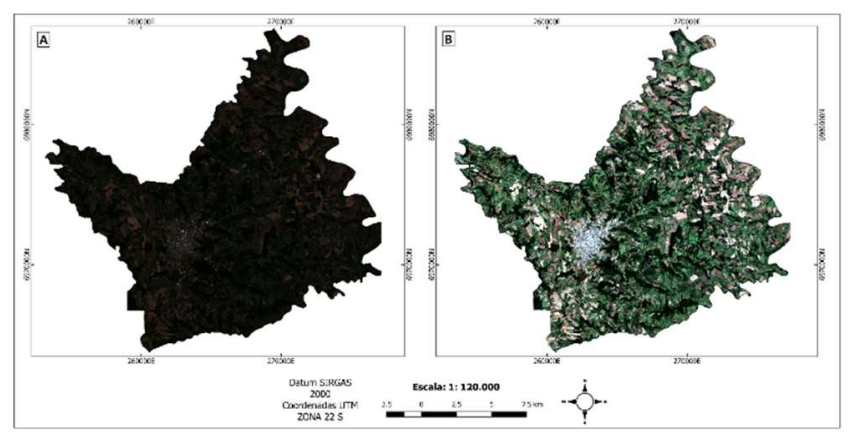

Figura 2. Imagem multibanda recortada de Frederico Westphalen - RS, composição cor verdadeira R3G2B1: A sem realce e $\mathrm{B}$ - com realce $2 \%$.

Figure 2. Frederico Westphalen - RS multi-banded cropped image, true color composition R3G2B1: A - no enhancement and $\mathrm{B}$ - with $2 \%$ enhancement.

Realizou-se na segunda parte a vetorização das feições, obtendo então o mapa visual que conteve as cinco classes temáticas (Vegetação Arbórea, Vegetação Rasteira, Área Urbanizada, Solo Exposto e Corpos Hídricos).

A Figura 3 apresenta esse mapa de interpretação visual, considerado, neste trabalho, como verdade de campo, e a Tabela 2 as informações referentes à área, em $\mathrm{km}^{2}$, de cada uma dessas classes temáticas e a proporção, em porcentagem, em relação ao tamanho do município. 


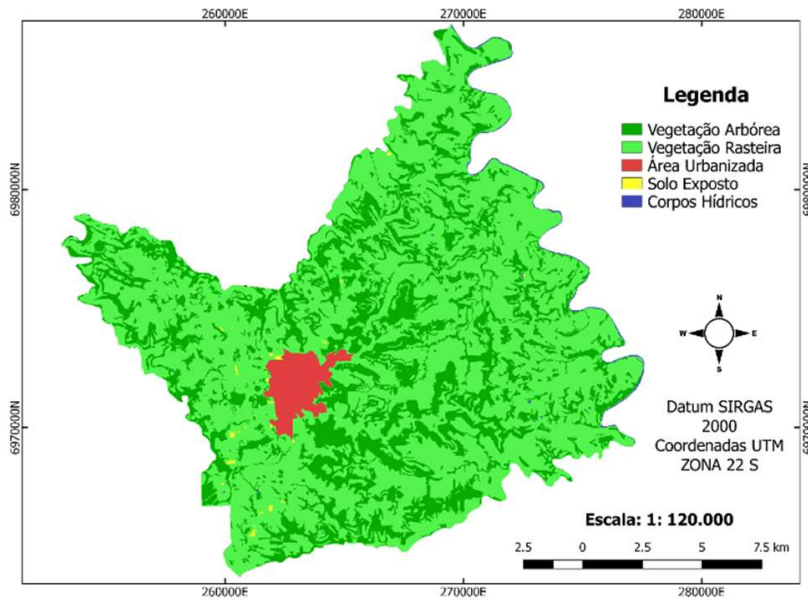

Figura 3. Mapa base obtido por meio da interpretação visual da imagem de satélite Sentinel 2A.

Figure 3. Base map obtained through the visual interpretation of the Sentinel 2A satellite image.

Pela Tabela 2, no mapa verdade de campo, a vegetação rasteira é a classe com o maior valor de área $\left(177,35 \mathrm{~km}^{2}\right)$, seguida da vegetação arbórea $\left(79,44 \mathrm{~km}^{2}\right)$, da área urbanizada $\left(6,78 \mathrm{~km}^{2}\right)$, dos corpos hídricos $\left(1,17 \mathrm{~km}^{2}\right)$ e por último o solo exposto $\left(0,47 \mathrm{~km}^{2}\right)$. Na terceira etapa obteve-se as classificações e seus mapas, iniciando com a mínima distância para o método supervisionada (Figura 4.A) e a ISODATA para a não supervisionada (Figura 4.B).

Tabela 2. Área em $\mathrm{km}^{2}$ e $\%$ das classes temáticas do mapa visual.

Table 2. Area in $\mathrm{km}^{2}$ and $\%$ of the thematic classes of the visual map.

\begin{tabular}{lcc}
\hline \multicolumn{1}{c}{ Classes temáticas } & \multicolumn{2}{c}{ Área } \\
\hline & $\mathrm{Km}^{2}$ & $\%$ \\
\hline Vegetação Arbórea & 79,44 & 29,95 \\
Vegetação Rasteira & 177,35 & 66,87 \\
Área Urbanizada & 6,78 & 2,56 \\
Solo Exposto & 0,47 & 0,18 \\
Corpos Hídricos & 1,17 & 0,44 \\
\hline \multicolumn{1}{c}{ Soma } & 265,21 & 100 \\
\hline
\end{tabular}

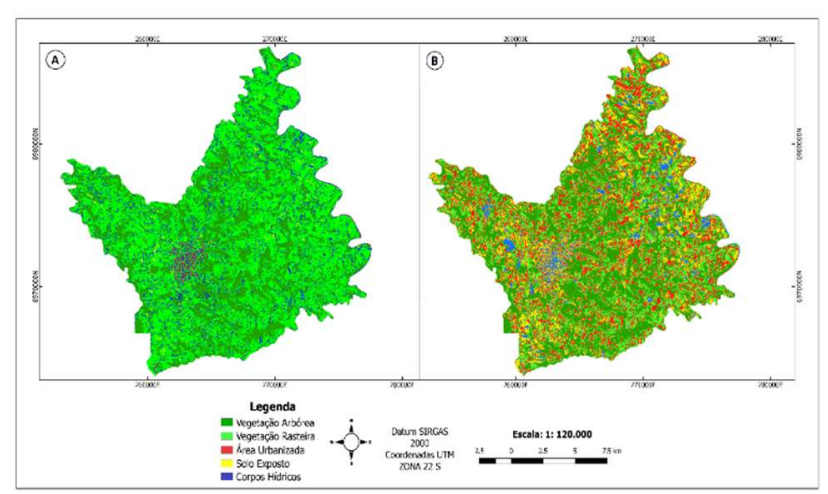

Figura 4. Mapas temáticos das classificações supervisonada (A) e não supervisionada (B), com base nas 5 classes temáticas.

Figure 4. Thematic maps of supervised (A) and unsupervised (B) classifications, based on the 5 thematic classes.

A Tabela 3 apresenta as informações das duas classificações aplicadas, como também um comparativo dos resultados de área, em porcentagem, das classificações com os dados obtidos do mapa visual.

Para Junior; Ribeiro (2014) os erros estão presentes em qualquer tipo de classificação.

Assim, a Tabela 4 apresenta a matriz de confusão dos dados de validação cruzada entre o mapa supervisionado e o mapa verdade de campo, mostrando as classes temáticas em questão e relacionando uma dada classe a forma como foi classificada.

Utilizando os dados de validação cruzada para a aferição da acurácia temática, obteve-se um valor de $63,41 \%$ para a exatidão global, onde, aproximadamente, $36,59 \%$ dos pontos de amostragem foram classificados erroneamente, correspondendo a um índice Kappa de 0,45\%.

Já os dados da matriz de confusão dos dados de validação cruzada entre o mapa não supervisionado e o mapa verdade de campo são apresentados na Tabela 5 .

Tabela 3. Dados de área dos mapas verdade de campo (visual) e das classificações supervisonada (mínima distância) e não supervisionada (ISODATA).

Table 3. True-field (visual) and supervised (minimum distance) and unsupervised (ISODATA) area map data.

\begin{tabular}{lccccc}
\hline & Visual & \multicolumn{2}{c}{ Mínima Distância } & \multicolumn{2}{c}{ ISODATA } \\
\hline Classes temáticas & $\begin{array}{c}\text { Área } \\
\left(\mathrm{Km}^{2}\right)\end{array}$ & $\begin{array}{c}\text { Área } \\
\left(\mathrm{Km}^{2}\right)\end{array}$ & $\begin{array}{c}\text { Diferença } \\
(\%)\end{array}$ & $\begin{array}{c}\text { Área } \\
\left(\mathrm{Km}^{2}\right)\end{array}$ & $\begin{array}{c}\text { Diferença } \\
(\%)\end{array}$ \\
\hline Vegetação Arbórea & 79,44 & 77,38 & $-0,78$ & 89,77 & 3,9 \\
Vegetação & 177,35 & 153,38 & $-9,04$ & 75,32 & $-38,47$ \\
Rasteira & & 28,68 & 8,25 & 53,39 & 17,58 \\
Área Urbanizada & 6,78 & 2,5 & 0,77 & 35,03 & 13,03 \\
Solo Exposto & 0,47 & 2,5 & 0,79 & 11,69 & 3,97 \\
Corpos Hídricos & 1,17 & 3,28 & & & \\
\hline
\end{tabular}

Tabela 4. Matriz de confusão para a análise da acurácia obtida na classificação supervisionada mínima distância, com informações de acurácia e erros de produtor e usuário.

Table 4. Confusion matrix for the analysis of accuracy obtained in supervised minimum distance classification, with accuracy and producer and user errors.

\begin{tabular}{ccccccccc}
\hline & A & B & C & D & E & I & J & K \\
\hline A & 47 & 2 & 1 & 0 & 3 & 53 & 88,68 & 11,32 \\
B & 10 & 56 & 0 & 3 & 4 & 73 & 76,71 & 23,29 \\
C & 0 & 14 & 0 & 5 & 1 & 20 & 0,00 & 100,00 \\
D & 2 & 2 & 1 & 0 & 8 & 13 & 0,00 & 100,00 \\
E & 0 & 2 & 1 & 1 & 1 & 5 & 20,00 & 80,00 \\
\hline F & 59 & 76 & 3 & 9 & 17 & 164 & & \\
\hline G & 79,66 & 73,68 & 0,00 & 0,00 & 5,88 & & & \\
\hline H & 20,34 & 26,32 & 100,0 & 100,0 & 94,12 & & & \\
\hline
\end{tabular}

$\mathrm{A}=$ Vegetação Arbórea; $\mathrm{B}=$ Vegetação Rasteira; $\mathrm{C}=$ Solo Exposto; $\mathrm{D}=$ Corpos Hídricos; $\mathrm{E}=$ Área Urbanizada; $\mathrm{F}=$ Soma Colunas; $\mathrm{G}=$ Acurácia Produtor (\%); H = Erro Omissão (\%); I = Soma Linhas; J = Acurácia Usuário $(\%) ; \mathrm{K}=$ Erro Comissão (\%).

\section{DISCUSSÃO}

As duas classificações, tanto supervisionada quanto não supervisionada, possuem suas relevâncias em relação a classificação e a depender do critério estabelecido em pesquisa, bem como da escala usada. Mas em trabalhos com áreas de estudo onde o recorte é pequeno e os detalhes precisam ser otimizados, além de poucas cenas, o reconhecimento das classes se torna mais acurado numa classificação supervisionada do que em uma não supervisionada (SILVA et al., 2013). 
Tabela 5. Matriz de confusão para a análise da acurácia obtida na classificação não supervisionada ISODATA, com informações de acurácia e erros de produtor e usuário.

Table 5. Confusion matrix for the analysis of the accuracy obtained in the ISODATA unsupervised classification, with information of accuracy and errors of producer and user.

\begin{tabular}{ccccccccc}
\hline & A & B & C & D & E & I & J & K \\
\hline A & 50 & 0 & 1 & 1 & 0 & 52 & 96,15 & 3,85 \\
B & 13 & 25 & 17 & 14 & 4 & 73 & 34,25 & 65,75 \\
C & 0 & 3 & 2 & 7 & 8 & 20 & 10,00 & 90,00 \\
D & 5 & 4 & 1 & 1 & 3 & 14 & 7,14 & 92,86 \\
E & 0 & 0 & 1 & 3 & 1 & 5 & 20,00 & 80,00 \\
\hline F & 68 & 32 & 22 & 26 & 16 & 164 & & \\
\hline G & 73,53 & 78,13 & 9,09 & 3,85 & 6,25 & & & \\
\hline H & 26,47 & 21,88 & 90,91 & 96,15 & 93,75 & & & \\
\hline
\end{tabular}

A = Vegetação Arbórea; $\mathrm{B}=$ Vegetação Rasteira; $\mathrm{C}=$ Solo Exposto; $\mathrm{D}=$ Corpos Hídricos; $\mathrm{E}=$ Área Urbanizada; $\mathrm{F}=$ Soma Colunas; $\mathrm{G}=$ Acurácia Produtor (\%); H = Erro Omissão (\%); I = Soma Linhas; J = Acurácia Usuário (\%); K = Erro Comissão (\%).

Na classificação mínima distância, a vegetação rasteira foi a que obteve o maior valor em área $\left(153,38 \mathrm{~km}^{2}\right)$, seguida das classes vegetação arbórea $\left(77,38 \mathrm{~km}^{2}\right)$, área urbanizada $(28,68$ $\left.\mathrm{km}^{2}\right)$, corpos hídricos $\left(3,28 \mathrm{~km}^{2}\right)$ e solo exposto $\left(2,50 \mathrm{~km}^{2}\right)$.

Diferente para o que foi encontrado na classificação ISODATA onde os maiores valores em área foram da vegetação árbórea $\left(89,77 \mathrm{~km}^{2}\right)$, vegetação rasteira $\left(75,32 \mathrm{~km}^{2}\right)$, área urbana $\left(53,39 \mathrm{~km}^{2}\right)$, solo exposto $\left(35,05 \mathrm{~km}^{2}\right)$ e corpos hídricos $\left(11,69 \mathrm{~km}^{2}\right)$.

Já em relação a comparação da classificação mínima distância com a interpretação visual, em ambos os métodos, foram obtidas a mesma sequência de ordem sobre as classes temáticas em relação aos maiores valores de área, sendo que as maiores diferenças percentuais foram para as classes vegetação rasteira (com diferença de $-9,04 \%$ ), área urbanizada $(8,25 \%)$, corpos hídricos $(0,79 \%)$, vegetação arbórea $(-0,78 \%)$ e solo exposto $(0,77 \%)$.

Para a comparação da ISODATA com a verdade de campo, a sequência de ordem sobre as classes temáticas foram diferentes, onde para a classificação ISODATA as maiores áreas foram visualizadas de acordo as classes temáticas vegetação arbórea (com diferença de 3,90\%), vegetação rasteira $(-38,47 \%)$, área urbana $(17,58 \%)$ e solo exposto $(13,03 \%)$.

Visualizando os dados obtidos, podemos afirmar em questão de valores de área, que a classificação mínima distância foi a que mais se aproximou dos valores do mapa verdade de campo (concordância) enquanto os valores da ISODATA foram bastantes dispersos em classes errôneas, principalmente nas áreas urbanas, solo exposto e corpos hídricos.

Como a imagem era de um período agrícola de plantio, havia a existência de muitas áreas com palhada no solo, se enquadrando no mapa visual, conforme as característica das classes temática de Ferreira et al. (2017), em vegetação rasteira, e devido a isso, o classificador compreendeu ser solo exposto, por haver uma tonalidade bem próxima ao marrom.

Outra confusão de classificação foi em relação aos corpos hídricos, devido haver ao nordeste da área de estudo, o rio da Várzea que representa o limite do município. O rio apresentou coloração voltada ao tom de marrom escuro na imagem de satélite, em que a classificação não supervisionada enquadrou esses pixels do corpo d'água, como solo exposto. O mesmo equívoco de classificação ocorreu nos estudos de Lopes (2018); Barbosa, Furrier (2014); Mello et al. (2012).

Mesmo desacordo com a área urbana por possuir coloração clara voltada ao branco. Como a palhada e alguns pontos do rio haviam refletância desses objetos, comparando o mapa de interpretação visual com a classificação ISODATA, visualizou-se que em alguns pontos de vegetação rasteira e corpos hídricos foram classificados como área urbana. Situação similar ocorreu no trabalho de Silva et al. (2017).

É válido comentar que, quanto melhor a resolução espacial do sistema sensor, dada a alta quantidade de pixels, maior a discriminação de outros objetos intrínsecos na amostra, o que provoca maior variabilidade espectral em uma mesma classe (MENDES et al., 2015).

Por meio da matriz apresentada acima, pode-se observar a exatidão do mapeamento, onde os valores da diagonal principal (em negrito) referem-se à porção das amostras, em pixel, de cada classe corretamente classificada. Assim, para o método supervisionado, as maiores porcentagens de acerto foram para as classes vegetação arbórea e vegetação rasteira, seguidos das classes área urbanizada que apresentou valor muito baixo em relação as classes já citadas. Já nas classes solo exposto e corpos hídricos, não houve acertos.

$\mathrm{O}$ uso da matriz de erro permite, entre outros, alcançar os objetivos como o ajuste das áreas das classes obtidas por algum tipo de classificação, o cálculo de parâmetros de exatidão geral da classificação, e a identificação de erros específicos que afetam cada uma das categorias (MENDES et al., 2015).

Assim, essa matriz nos permite constatar que algumas classes foram desprovidas de erros de omissão e comissão, sendo as maiores encontradas nas classes solo descoberto e corpos hídricos $(100,00 \%)$, e área urbana $(87,05 \%)$. Outras classes obtiveram alguns erros, mas em valores pouco expressivos, sendo de $15,82 \%$ para vegetação arbórea e $24,80 \%$ vegetação rasteira.

Segundo a classificação de Landis; Kock (1977), os valores encontrados são considerados de boa aceitação, e a justificativa do valor do índice Kappa ser menor que a exatidão global se dá pelo fato de o índice Kappa considerar todas as células da matriz de erro, mesma situação encontrada no trabalho de Mendes et al. (2015).

Igualmente para a classificação mínima distância, a Tabela 5 trás em sua diagonal principal (negrito) os valores, em pixel, referentes à porção das amostras de cada classe corretamente classificadas.

Para a ISODATA se deu igualmente, ao classificador aplicado anteriormente, as classes de maiores valores de acertos - vegetação arbórea e vegetação rasteira.

Os menores valores de acerto ocorreram também nas classes corpos hídricos, área urbanizada e solo expostos, contudo, para a ISODATA em todas as classes houveram valores de acerto.

Observando esses resultados, percebe-se que a classe que apresentou os maiores erros de omissão e comissão foi a de corpos hídricos, com cerca de $94,5 \%$ dos pixels que deveriam ser assinalados à esta classe, foram assinaladas a outras. Situação semelhante foi notada para as classes solo exposto e área urbanizada, que tiveram grandes valores de pixels assinalados erroneamente - acima de $85 \%$.

Levando em conta a classificação de índices Kappa proposta por Landis; Koch (1977) foi considerado razoável, 
apresentando um acerto de aproximadamente $31 \%$, e com exatidão global de $48,17 \%$.

Brasileiro et al. (2018) também encontraram um valor considerado razoável para o índice Kappa, porém, recomendam a necessidade de um maior número de amostras para classificação, pois esse ocorrido leva o algoritmo a alocar pixels em classes indevidas, aumentando a imprecisão da classificação.

\section{CONCLUSÕES}

Baseando-se às taxas de amostras coletadas, bem como os valores gerados de área, a classificação supervisionada conseguiu estipular valores muito semelhantes com a validação feita pela inspeção visual, sendo que as classes predominantes no município de Frederico Westphalen são vegetação rasteira e a vegetação arbórea.

Já em relação a avaliação da acurácia, destaca-se novamente a classificação Mínima Distância, mais eficiente do que a ISODATA, por possuir as menores médias de erros, tanto de omissão quanto de comissão, além de melhores valores dos parâmetros estatísticos Kappa e Exatidão Global quando comparado com a imagem de referência, havendo um melhor reconhecimento das áreas classificadas/segmentadas.

Contudo, a classificação supervisionada não conseguiu acertar as classes solo exposto e corpo hídrico, mesmo que tenha obtido valores de áreas, em $\mathrm{km}^{2}$, próximos em relação a inspeção visual. Diferente do encontrado para o método não supervisionado, que obteve acertos em todas as classes temáticas.

Assim, mesmo utilizando boa resolução espacial e espectral da imagem em estudo, os parâmetros estatísticos não foram satisfatórios (índice Kappa abaixo de 60\% (LANDIS e KOCH; 1977) e exatidão global acima de 85\%; (JENSEN; 1986). Deste modo, demostra que para aumentar a eficiência de ambos os métodos, deve-se modificar a classes temáticas utilizadas, criando uma classificação para o local estudado, ou até mesmo modificar a composição colorida multibanda RGB para diferenciar melhor os alvos da imagem.

\section{REFERÊNCIAS}

ANDRADE, A. C.; FRANCISCO, C. N.; ALMEIDA, C. M. Desempenho de classificadores paramétrico e não paramétrico na classificação da fisionomia vegetal. Revista Brasileira de Cartografia, Uberlândia, v. 66, n. 2, p. 349-363, 2014.

BARBOSA, T. S.; FURRIER, M. Classificação multitemporal do uso e ocupação do solo do município do Conde - PB Revista Geo Amazônia, Belém, v. 2, n. 3, p. 113 - 122, 2014.

BERNARDI, H. V. F.; DZEDZEJ. M.; CARVALHO, L. M. T. de; ACERBI JUNIOR, F. W. Classificação digital do uso do solo comparando os métodos "pixel a pixel" e orientada ao objeto em imagem QuickBird. In: Simpósio Brasileiro de Sensoriamento Remoto, 12., 2007, Florianópolis. Anais... Florianópolis: INPE, 2007. p. 5595-5602.

BRASILEIRO, F. G.; OLIVEIRA, C. M. M.; RODRIGUES, R. A.; DELGADO, R. C. Classificação de imagem orbital pelo método máxima verossimilhança em Quixeramobim, Ceará, Brasil. Revista Geográfica Acadêmica, Boa Vista, v. 10, n. 1, p. 81-92, 2016.
CONGALTON, R. G.; GREEN, K. Assessing the accuracy of remotely sensed data: principles andpractices. 2. ed. Taylor \& Francs Group, 2009, 183 p.

EMATER/RS. Safra de Verão 2017/2018: Estimativas Iniciais de Área e Produção. Gerência de Planejamento, Núcleo de Informações e Análises. 2018. Disponível em: $<$ http://www.emater.tche.br/site/arquivos_pdf/safra/safra Tabela_30082017.pdf>. Acesso em: 01 jul. 2018.

FERREIRA, D. G.; ASSIS, E. S. de; KATZSCHNER, L. Construção de um mapa climático analítico para a cidade de Belo Horizonte, Brasil. Revista Brasileira de Gestão Urbana, v .9, n. 1.1, Curitiba, 2017.DOI: http://dx.doi.org/10.1590/2175-3369.009.supl1.ao01

GLATZLE, A. Questioning key conclusions of FAO publications 'Livestock's Long Shadow' (2006) appearing again in 'Tackling Climate Change Through Livestock' (2013). Pastoralism, v. 4, n. 1, p. 1-6, 2014. DOI: https://dx.doi.org/10.1186/2041-7136-4-1

IBGE INSTITUTO BRASILEIRO DE GEOGRAFIA E ESTATÍSTICA. Censo Demográfico IBGE 2010. 2010. Disponível em: <http://cidades.ibge.gov.br>. Acesso em: 28 jun. de 2018.

IBGE INSTITUTO BRASILEIRO DE GEOGRAFIA E ESTATÍSTICA. Área urbanizada 2015. 2015. Arquivo Shapefile. Disponível em: < https://www.ibge.gov.br/geociencias-novoportal/cartas-emapas/redes-geograficas/15789-areas-

urbanizadas.html $=\& \mathrm{t}=$ downloads $>$. Acesso em: 28 jun. de 2018

INPE INSTITUTO NACIONAL DE PESQUISAS ESPACIAIS. Manuais: tutorial de geoprocessamento do SPRING. São José dos Campos: INPE, 2018.

JENSEN, J. R. Sensoriamento remoto do ambiente: uma perspectiva em recursos terrestres. Tradução EPIPHANIO, J. C. N. São José dos Campos: Parênteses, 2009. $598 \mathrm{p}$.

JUNIOR, R. L. F.; RIBEIRO, G. P. Avaliação de classificação de imagens para mapeamento digital do Parque Nacional da Serra dos Órgãos (PARNASO). Revista Brasileira de Cartografia, Uberlândia, v. 66, n. 6, p. 1203-1213, 2014.

LANDIS, J. R.; KOCH, G. G. The measurement of observer agreement for categorical data. Biometrics, Washington, v. 33 , n. 1, p. 159-174, 1977 . DOI: https://dx.doi.org/10.2307/2529310

LOPES, L. H. M. Uso e cobertura do solo no município de Tailândia-PA utilizando o TM/LANDSAT e técnica de classificação não-supervisionada. Engevista, Rio de Janeiro, v. 10, n. 2, p. 126-132, 2018. DOI: https://dx.doi.org/10.22409/engevista.v10i2.219

MATSUKUMA, C. K. Análise comparativa de algoritmos de classificação não-supervisionada, no mapeamento do uso e cobertura do solo. 2002. 84f. Dissertação (Mestrado) - Escola Superior de Agricultura Luiz de Queiroz, Piracicaba, 2002.

MEER, F. D.; WERFF, H. M. A.; RUITENBEEK, F. J. A. Potential of ESA's Sentinel-2 for geological applications. Remote Sensing of Environment, New York, v. 148, n. 1, p. 124-133, 2014.

MELLO, A. Y. I. DE, ALVES, D. S., LINHARES, C. A., \& LIMA, F. B. DE. Avaliação de técnicas de classificação digital de imagens landsat em diferentes padrões de cobertura da terra em Rondônia. Revista Árvore, Viçosa, 
v. 36, n. 3, p. 537-547, 2012. DOI: http://dx.doi.org/10.1590/S0100-67622012000300016

MENDES, D. F.; SILVA, S. F.; FERRARI, J. L.; SANTOS, A. R.; GARCIA, R. F. Acurácia temática do classificador por máxima verossimilhança em imagem de alta resolução espacial do satélite geoeye-1. Nucleus, Ituverava, v. 12, n. $1, \quad$ p. $107 \quad-\quad 118, \quad 2015 . \quad$ DOI: http://dx.doi.org/10.3738/1982.2278.1011

OLIVEIRA, G. P.; TAVARES, B. A. C.; ARAUJO, F. C. M. D. O uso de imagens SENTINEL-2 e do software livre QGIS no zoneamento ambiental: um estudo de caso no município de São Bento, Paraíba, Nordeste do Brasil. In: PEREZ FILHO, A.; AMORIM, R. R. (Org.). Os Desafios da Geografia Física na Fronteira do Conhecimento. 1ed. Campinas: Instituto de Geociências - UNICAMP, 2017. p. 4871-4883.

SILVA, E. B.; FERREIRA, L. G.; ANJOS, A. F.; MIZIARA, F. A expansão da fronteira agrícola e a mudança na cobertura e uso da terra no centro-sul de Goiás, entre 1975 e 2010. Ateliê Geográfico, Goiânia, v. 7, n. 2, p. 116-138, 2013. DOI: https://dx.doi.org/10.5216/ag.v7i2.15660

SILVA, M. A. O.; LIPORACE, F. S. Detecção automática de nuvem e sombra de nuvem em imagens de sensoriamento remoto. Boletim de Ciências Geodésicas, Curitiba, v. 22, n. 2, p. 369- 388, 2016.

SILVA, M. de S.; BUENO, I. T.; ACERBI JÚNIOR, F. W.; BORGES, L. A. C.; CALEGARIO, N. Avaliação da cobertura do solo como indicador de gestão de recursos hídricos: um caso de estudo na sub-bacia do Córrego dos Bois, Minas Gerais. Engenharia Sanitaria e Ambiental, Rio de Janeiro, v. 22, n. 3, p. 445-452. 2017. DOI: http://dx.doi.org/10.1590/s1413-41522017149673

SOARES, D. O.; SANTOS, A. C.; SILVA, E. B. Análise das classificações supervisionada e não supervisionada com o uso de imagens Landsat 5 TM e RapidEye, e suas contribuições para o mapeamento do uso e cobertura do solo no Parque Nacional das Emas. Revista Brasileira Geomática, Curitiba, v. 4, n. 2, p. 117-122, 2016. DOI: http://dx.doi.org/10.3895/rbgeo.v4n2.5492

VALE, J. R. B.; COSTA, J. A.; SANTOS, J. F. S.; SILVA, E. L. S.; FAVACHO, A. T. Análise comparativa de métodos de classificação supervisionada aplicada ao mapeamento da cobertura do solo no município de Medicilândia, Pará. Revista InterEspaço, Grajaú, v. 4, n. 13, p. 26-44, 2018. DOI: http://dx.doi.org/10.18764/2446-6549.v4n13p26-44 